\title{
Symposium
}

\section{Longitudinal Research on Alcohol Problems: The Flow of Risk, Problems, and Disorder over Time}

\author{
Chaired by Robert A. Zucker, University of Michigan, Alcohol Research Center, Ann Arbor, MI, USA \\ Introduction \\ Robert A. Zucker, University of Michigan, Alcohol Research Center, Ann Arbor, MI, USA \\ Subtype Varlations in Famlilal Risk Constancy Over Early to Middlo Chlldhood in a High \\ Risk Population \\ C. Raymond Bingham, Department of Psychology, Michigan State University, East Lansing, MI, USA
}

Cross Sectlonal vs. Longitudinal Examinations of Individual, Parent, and Peer Influences on Alcohol Misuse During Adolescence: Time for the Pain?

John E. Schulenberg, Institute for Social Research, University of Michigan, Ann Arbor, MI, USA

\author{
Predicting Change In Problem Drinking in Young Adulthood: What Cross-Sectlonal Analysis \\ Can't Tell You \\ John E. Donovan, Department of Psychiatry and Adolescent Alcohol Research Center, University of Pittsburgh \\ School of Medicine, Pittsburgh, PA, USA
}

Husbands and Wives Drinking: Unilateral or Bllateral Influences

Kenneth Ex Leonard, Research Institute on Addictions, Butfalo, NY, USA

\author{
Consistency In the Relationship Between Level of Response to Alcohol and Alcohollsm \\ Risk Across a Decade \\ Marc A. Schuckit, Alcohol Research Center, Department of Psychiatry, VAMC, San Diego, CA, USA \\ Discussant \\ Kenneth J. Sher, Department of Psychology, University of Missouri, Columbia, MO, USA
}

\section{INTRODUCTION}

Longitudinal research designs are still uncommon among alcohol researchers, yet they are the method of choice for establishing causal sequencing in complex human studies of the etiology of alcohol problems and alcoholism. Contributors to this symposium had two goals: (1) to highlight how this methodology will sometimes uncover findings about the causal structure of problematic alcohol(ic) outcomes that are divergent from those produced by cross sectional data bases; (2) to provide a sampling of some of the most interesting longitudinal studies currently in process, that are tracking the emergence, stability, and change in alcohol problems/alcoholism over periods ranging from 2 to 10 years, and developmental periods from early childhood to middle adulthood.

\section{DISCUSSION}

Subtype Variations in Familial Risk Constancy Over Early to Middle Childhood in a High Risk
Population. Bingham, Zucker and Hiram Fitzgerald compared cross-sectional and longitudinal findings of variation in family risk load for the children's later substance abuse, based upon observations of child risk at ages 3-5, and again at ages 6-8. Subjects were participants in a prospective community study of boys and their parents in families with an without an alcoholic father. Child externalizing problems were used as the most direct proxy indicator for later alcohol problem use, but other indices of child behavior difficulty were also assessed and evaluated. Familial alcoholism subtype differences based upon level of antisocial behavior in the alcoholic fathers, 1,2 were strongly related to a composite risk load indicator of parents' alcohol use, other psychopathology, as well as measures of adaptive and social funcitoning adequacy among the parents. Although family subtype mean differences in risk load suggested that family risk might remain constant across waves, in actuality there were substantial within-group quantitative and qualitative shifts which indicated that child risk burden was comparatively fluid over time, even within high risk populations. Nonetheless, childen from antisocial alcoholic, nonantisocial alcoholic and control families differed in level of 
behavior problems, as well as in pattern of behavior problem developement. The group most likely to sustain risk were those children out of antisocial alcoholic families.3,4

Cross-Sectional vs. Longitudinal Examinations of Individual, Parent, and Peer Influences on Alcohol Misuse During Adolescence: Time for the Pain? Schulenberg, Kate Wadsworth, Amy Burchart and Jennifer Maggs contrasted the influences of individual, parent and peer characteristics on alcohol misuse during adolescence via cross-sectional and longitudinal analyses of a large scale, community based study of adolescents assessed at Grades 6, 7, 8 and 10, who were part of the Alcohol Misuse Prevention Study. Constructs assessed included parental monitoring and nurturance, deviancy of self image, peer and parental alcohol use, susceptibility to peer pressure to misbehavior, alcohol misuse, and peer disapproval of alcohol misuse. Using structural equation modelling, substantial cross-sectional correlations were found among all constructs, but peer drinking was the most powerful predictor of adolescent alcohol misuse; moreover, this relationship was stronger among older adolescents than younger ones. Also, within-time analyses indicated that lack of parental monitoring, as well as susceptibility to peer pressure, were important predictors. Finally, deviant self image was related to greater misuse among the younger but not the older children.

In contrast, the longitudinal analyses showed that susceptibility to peer pressure was the only predictor of increasing alcohol misuse over time; both parental monitoring and deviant self image no longer were predictive. These results indicate that essential information about developmental processes relating to the onset and maintenance of alcohol misuse are missing when processes are assessed crosssectionally. In addition, such results may also be misleading about the nature of the causal structure involved.

Proximal vs. Distal Predictors in Longitudinal Analyses of Young Adult Drinking-Driving. Donovan examined the influence of personality, social environment, and behavior variables on differences in drinking and driving measured over a two year interval in a representative, statewide sample of 18-24 year old licensed drivers in Colorado. 7 Of special interest was the relative predictive role played by distal variables reflecting psychosocial and behavioral un-conventionality vs. the role of more proximal variables reflecting attitudes about drinking-driving upon later behavioral outcomes. ${ }^{7,8}$ Contrary to the hypotheses, distal measures reflecting conventionality-unconventionality accounted for more of the variance in both young adult drinking and driving, in both the cross-sectional and longitudinal analyses. The study underscored the need for a conceptual framework for measurement and prediction that encompasses those superficially more distal characteristics that bear a compelling link to the dependent variable, even if they do not refer to it directly.

Husbands and Wives Drinking: Unilateral or Bilateral Influences. Leonard and Rina Das Eiden reported on a prospective, study that has been tracking the relationship and drinking patterns of initially newly married couples, and the manner in which changes in these relationships are attributable to assortative mating, to the marital transition, or to the unilateral or bilateral influences of each spouse upon the other. The study follows up on earlier work ${ }^{9}$ which observed a decline in alcohol use over the marriage transition for both men and women. However, not all couples decrease their drinking; moreover, some changes in drinking patterns are plausibly a function of spousal influence, although only one earlier study 10 has examined this issue. Couples from the Buffalo Newlywed Study, a prospective study of newly married couples between 18 and 29 years of age, were assessed and monitored premaritally, and at 1st and 3rd anniversary. Husbands' and wives' premarital alcohol use was significantly correlated; husbands premarital alcohol use had a significant influence on wives's use one year after marriage but wives' use did not influence husbands' use. There were no significant partner influences from year 1 to 3, although residuals for husband and wife for Wave 1 to Wave 2, and Wave 2 to Wave 3 were correlated, indicating that both husband and wife drinking is moderately similarly influenced by other adult events (e.g., getting a new job, having a child).

Consistency in the Relationship Between Level of Response to Alcohol and Alcoholism Risk Across a Decade. Schuckit reported on the methodology and 8 year follow-up data on a prospective study of genetic and environmental factors that contribute to the risk for alcoholism, drug dependence, and other psychiatric disorders. $11,12,13$ Over a 10 year period (1978-88), 45318 to 29 year old sons of alcoholics and controls were identified and evaluated on personality variables, intensities of response to alcohol, and alcohol metabolism. At that time, $40 \%$ of FH+ and only $10 \%$ of FH- Ss demonstrated a low intensity of response to alcohol challenge. 8.5 years thereafter, a follow-up assessment was successfully implemented on 450 of the study participants. At this point, approximately $50 \%$ of the Ss had developed some adverse consequence related to alcohol (e.g., blackouts) with almost $40 \%$ of the $\mathrm{FH}+$ group developing alcohol abuse/dependence during the follow-up period, but only $15 \%$ of the FH- group. Data are consistent with the conclusion that level of reaction to alcohol may be a mediator of alcoholism risk. Moreover, in this instance cross sectional associations observed in early adulthood were consistent with prospective relationships 8.5 years later.

\section{SIGNIFICANCE}

These presentations underscore the complexity of current etiologic models for the development of alcohol use and alcohol problems, 14,15,16 and emphasize the need for microanalytic developmental models of process. They form part of a now burgeoning literature that casts a variable net ranging all the way from neuroadaptive structures to expectancy theory, where investigators have become involved in the painstaking process of disaggregating which structures play what role at 
different developmental epochs. In this regard, it is interesting to note that the studies showing greatest parallelism across time (Bingham et al, Schuckit) were also those where initial level of risk was greatest, and where the observed outcome in one instance (Schuckit) was alcohol abuse/dependence, and in the other instance (Bingham et al), where the anticipated outcome would also be high levels of alcohol abuse/ dependence. Conceivably risk may be more fluid over time in populations involving low to midrange levels of risk.

These studies also underscore the importance of a time dynamic in understanding linkages of supposedly causal structures, and as longitudinal evidence becomes more available, our notions of what drives mechanisms of abuse are likely to substantially change.

\section{SELECTED REFERENCES}

1. Zucker RA, Ellis DA, Fitzgerald HE: Developmental evidence for at least two alcoholisms, I: Biopsychosocial variation among pathways into symptomatic difficulty. Ann NY Acad Sci 708:134-146, 1994

2. Zucker RA, Ellis DA, Fitzgerald HE, Bingham CR, Sanford K: Other evidence for at least two alcoholisms II: Life course variation in antisociality and heterogeneity of alcoholic outcome. Develop Psychopath 1996 (in press)

3. Zucker RA, Ellis DA, Bingham CR, Fitzgerald HE: The development of alcoholic subtypes: Risk variation among alcoholic families during the early childhood years. Alcohol Health Res World 20:46-54, 1996

4. Bingham CR, Zucker RA, Fitzgerald HE: Risk load variation and its association with problem behavior development among the sons of alcoholics. East Lansing and Ann Arbor MI: Michigan State University-University of
Michigan Longitudinal Study, 1996

5. Dielman TE: School-based research on the prevention of adolescent alcohol use and misuse: Methodolgical issues and advances. J Res Adolescence 4:271-293, 1994

6. Schulenberg JE, Kloska DD, Maggs J, Shope JT, Zucker RA: Timing matters: The differential long term effectiveness of an alcohol misuse prevention program. Ann Arbor, MI: Institute for Social Research. University of Michigan, 1996 (ms under revision)

7. Donovan JE: Young adult drinking-driving: Behavioral and psychosocial correlates. J Stud Alcohol 54:600-613, 1993

8. Jessor R, Jessor, SL: Problem Behavior and Psychosocial Development: A Longitudinal Study of Youth. San Diego, CA, Academic Press, 1977

9. Miller-Tutzauer C, Lecnard KE. Windle M: Marriage and alcohol use: A longitudinal study of maturing out. J Stud Alcohol 52:434-440, 1990

10. Moos RH, Fínney JW, Cronkite RC: Alcoholism Treatment: Context, Process, and Outcome. NY, Oxford, 1990

11. Schuckit MA, Smith TL: An 8-year follow-up of 450 sons of alocholics and controls. Arch Gen Psychiatry 53:202-210, 1996

12. Schuckit MA: Low level of response $t$ alcohol as a predictor of future alcoholism. Am J Psychiatry 151:184-189, 1994

13. Twitchell GR, Hertzog CA, Klein JK, Schuckit MA: The anatomy of a follow-up. Br J Addict 87:251-157, 1992

14. Edwards G, Arif A, Hodgson R: Nomenclature and classification of drug- and alcohol-related problems. A WHO Memorandum. Bull WHO 99:225, 1981

15. Sher KJ: Children of Alcoholics: A Research Perspective. Chicago, University of Chicago Press, 1991

16. Zucker RA: Pathways to alcohol problems and alcoholism: A developmental account of the evidence for multiple alcoholisms and for contextual contributions to risk, in Zucker RA, Boyd GM, Howard J (eds): The Development of Alcohol Problems: Exploring the Biopsychosocial Matrix of Risk, NIAAA Research Monograph 26, Chapter 13. Rockville, MD, Department of Health and Human Services, 1994, pp 255-289 